\title{
Effect of Activation Mode on Flexural Strength and Elasticity Modulus of Dual Cure Resin Cements
}

\section{Efecto del modo de activación en la resistencia a flexión y módulo de elasticidad de cementos de resina de polimerización dual}

Isadora R. Guimaraes DDS, MSc, PhD¹; Fabián Murillo Gómez DDS, MScㅜ; Mario F. De Goes DDS, MSc, PhD1

1. Department of Restorative Dentistry, Dental Materials Area, Piracicaba Dental School, University of Campinas, Piracicaba, SP, Brazil.

Correspondence to: Dr. Mario F. De Goes - degoes@fop.unicamp.br

Received: 4-III-2016

Accepted: 15-III-2016

Published Online First: 17-III-2016

DOl: $\quad$ http://dx.doi.org/10.15517/ijds.v0i0.23556

\section{ABSTRACT}

Objective: This study evaluated the effect of the activation mode on flexural strength and elasticity modulus of four dual cure resin-based cements. Methods: Two self-adhesive resin cements (Clearfil SA Cement (CSA) and RelyX U100 (U)) and two conventional resin cements (Clearfil Esthetic Cement (CE)and RelyX ARC (ARC)) were used to produce a total of 45 bar specimens $(7 \times 2 \times 2 \mathrm{~mm})$ using three different activation modes $(n=15)$ : Direct light-cure (D), Indirect light-cure using a $2 \mathrm{~mm}$ composite resin barrier (I) and Self-cure (S). Three-point flexural tests were performed after 24 hours water storage at $37^{\circ} \mathrm{C}$, using a universal testing machine (Instron) at a cross-speed of $0.5 \mathrm{~mm} / \mathrm{min}$ until fracture. Flexural strength (MPa) and elasticity modulus values were subjected to ANOVA and Tukey's Test $(\alpha=0.05)$. Results: Data revealed that light polymerized groups presented statistically higher flexural strength $(\mathrm{CSA} / \mathrm{D}=113.63 \pm 19.65 ; \mathrm{CSA} / \mathrm{l}=80.66 \pm 23.74 ; \mathrm{U} / \mathrm{D}=101.33 \pm 9.8 ; \mathrm{U} / \mathrm{l}=94.96 \pm 36.9 ; \mathrm{CE} / \mathrm{D}=219.08$ $\pm 39.94 ; \mathrm{CE} / \mathrm{l}=226.42 \pm 34.59 ; \mathrm{ARC} / \mathrm{D}=150.03 \pm 26.15 ; \mathrm{ARC} / \mathrm{l}=111.78 \pm 14.28)$ and also elasticity modulus values $(\mathrm{CSA} / \mathrm{D}=2.9 \pm 0.6 ; \mathrm{CSA} / \mathrm{I}=1.5 \pm 0.4 ; \mathrm{U} / \mathrm{D}=2.9 \pm 0.5 ; \mathrm{U} / \mathrm{I}=2.6 \pm 1.4 ; \mathrm{CE} / \mathrm{D}=$ $6.5 \pm 1.3 ; \mathrm{CE} / \mathrm{I}=5.8 \pm 1.0 ; \mathrm{ARC} / \mathrm{D}=4.2 \pm 0.93 ; \mathrm{ARC} / \mathrm{I}=2.5 \pm 0.5$ ) compared to self-cured groups (flexural strength: $\mathrm{CSA} / \mathrm{S}=65.81 \pm 21.84 ; \mathrm{U} / \mathrm{S}=53.62 \pm 28.73 ; \mathrm{CE} / \mathrm{S}=129.02 \pm 51.67 ; \mathrm{ARC} / \mathrm{S}=77.98$ \pm 19.61 and elasticity modulus: $\mathrm{CSA} / \mathrm{S}=1.4 \pm 0.5 ; \mathrm{U} / \mathrm{S}=1.2 \pm 0.7 ; \mathrm{CE} / \mathrm{S}=2.2 \pm 1.5 ; \mathrm{ARC} / \mathrm{S}=$ $1.0 \pm 0.5$ ). The usage of a composite resin barrier only affected the mechanical properties of ARC and CSA. Conventional resin cements presented higher flexural strength values than the self-adhesive cements. CE presented the highest values compared to all other cements. No statistical difference was observed between self-adhesive cements. Conclusion: Light-curing of resin luting cements produced higher flexural strength for all tested materials. Similar mechanical behavior was observed for the tested self-adhesive cements.

\section{KEYWORDS}

Dual cure resin-based cement; Self-adhesive cement; Activation mode;

Flexural strength; Modulus of elasticity.

GUIMARAES I., MURILLO F., DE GOES M., 2016: Effect of Activation Mode on Flexural Strength and Elasticity Modulus of Dual Cure Resin Cements.ODOVTOS-Int. J. Dental Sc., 18-1 (January-April): 61-71. 


\section{RESUMEN}

Objetivo: Este estudio evaluó el efecto de diferentes métodos de polimerización en la resistencia a flexión y el módulo de elasticidad de cuatro cementos resinosos de polimerización dual. Métodos: Dos cementos resinosos autoadhesivos (Clearfil SA Cement (CSA) y RelyX U100 (U)) y dos convencionales (Clearfil Esthetic Cement (CE) y RelyX ARC (ARC)) fueron utilizados para fabricar un total de 45 cuerpos de prueba en forma de barra $(7 \times 2 \times 2 \mathrm{~mm})$ utilizando tres métodos de polimerización $(\mathrm{n}=15)$ : Luz directa (D), Luz indirecta (I) (utilizando una barrera de resina pre-polimerizada de $2 \mathrm{~mm}$ de espesura) y Autopolimerización (S). Después de 24 horas de almacenamiento en agua destilada a $37^{\circ} \mathrm{C}$, las muestras fueron sometidas a la prueba de resistencia a flexión de tres puntos con la ayuda de una máquina de ensayos universal (Instron) a una velocidad de $0.5 \mathrm{~mm} / \mathrm{min}$ hasta ocurrir la fractura. Los valores de resistencia a flexión y de módulo de elasticidad fueron analizados con las pruebas de Análisis de Variancia para dos factores y la prueba de comparaciones múltiples de Tukey $(\mathbf{a}=0.05)$. Resultados: Los datos obtenidos revelaron que los grupos que fueron polimerizados con luz, presentaron valores de resistencia a flexión $(C S A / D=113.63 \pm 19.65 ; C S A / I=80.66 \pm 23.74 ; U / D=101.33 \pm 9.8 ; U / I=94.96$ \pm 36.9; $C E / D=219.08 \pm 39.94 ; C E / I=226.42 \pm 34.59 ; A R C / D=150.03 \pm 26.15 ; A R C / I=111.78 \pm$ 14.28) y módulo de elasticidad (CSA/D = 2.9 $\pm 0.6 ; \mathrm{CSA} / \mathrm{I}=1.5 \pm 0.4 ; \mathrm{U} / \mathrm{D}=2.9 \pm 0.5 ; \mathrm{U} / \mathrm{I}=2.6$ $\pm 1.4 ; \mathrm{CE} / \mathrm{D}=6.5 \pm 1.3 ; \mathrm{CE} / \mathrm{I}=5.8 \pm 1.0 ; \mathrm{ARC} / \mathrm{D}=4.2 \pm 0.93 ; \mathrm{ARC} / \mathrm{I}=2.5 \pm 0.5$ ) mayores a los grupos auto-polimerizados (resistencia a flexión: $C S A / S=65.81 \pm 21.84 ; \mathrm{U} / \mathrm{S}=53.62 \pm 28.73$; CE/ $\mathrm{S}=129.02 \pm 51.67 ; \mathrm{ARC} / \mathrm{S}=77.98 \pm 19.61$ y módulo de elasticidad: $\mathrm{CSA} / \mathrm{S}=1.4 \pm 0.5 ; \mathrm{U} / \mathrm{S}=1.2$ $\pm 0.7 ; \mathrm{CE} / \mathrm{S}=2.2 \pm 1.5 ; \mathrm{ARC} / \mathrm{S}=1.0 \pm 0.5)$. El uso de una barrera de resina pre-polimerizada para la polimerización indirecta de los cementos, sólo afectó las propiedades mecánicas de ARC y CSA. Los cementos resinosos convencionales presentaron valores mayores de resistencia a flexión que los autoadhesivos. Conclusión: Polimerización por medio de luz produjo valores más altos de los parámetros mecánicos evaluados para todos los materiales utilizados. El comportamiento mecánico de ambos cementos resinosos autoadhesivos fue similar.

\section{PALABRAS CLAVE}

Cementos resinoso dual; Cementos autoadhesivos; Métodos de polimerización;

Resistencia a flexión; Módulo de elasticidad.

\section{INTRODUCTION}

Composite resin cement has been established as the preferred material for luting indirect restorations in recent years. This has occurred due to advances in physical properties, significant improvements in aesthetic characteristics, handling and easy application technique (1). Composite resin cements present advantages when compared to water-based luting cements. They offer better physical properties such as higher values of tensile and compressive strength, fracture toughness, low solubility in oral fluid, and they are available in different shades (2).

Polymerization of resin cements has been shown to be faster and more reliable using a visible light unit, which produce a much higher bond strength compared with the chemically cured materials (3). However, there are several clinical situations where light curing of composites is quite impractical or impossible. One of these situations may be when a composite/resin cement are used as core material or to lute opaque restorations or 
root canal posts. In these situations, bonding is mainly achieved by the self-curing mechanism (4). Nevertheless, some dual-cure resin cements are dependent primarily on light activation, and therefore somewhat lower mechanical properties are expected when exposed to low irradiance or when light from the curing unit is not available at all $(5,6,7)$. Another factor that may attenuate the light reaching the resin cement is the thickness of indirect restorative materials (8), beyond the distance of the light source (9). This decreased light intensity reaching the composite/resin cement, produce a lower maximal curing rate and lower mechanical properties on the material (10).

Self-adhesive resin cements have been developed in order to simplify the bonding procedure as they eliminate the needing of performing adhesive pretreatment on the tooth. This innovative type of cements claim to be less technique sensitive, as they reduce the steps for luting procedures and are less likely to cause postoperative sensitivity, because dentinal smear layer and smear plugs are not removed $(11,12,13)$. However, one previous study demonstrated that the degree of conversion rate obtained by one selfadhesive cement polymerized via self-curing method was $48 \%$, while when it was light polymerized this rate was about $54 \%$ (14). Thus, self-adhesive resin cements may also present inadequate polymerization when left to be self-cured, as well as conventional resin cements.

Flexural strength and elasticity modulus are useful basic parameters for the assessment of mechanical characteristics of dental materials. The failure resistance of cemented restorations under applied forces is related to the mechanical properties of the individual parts, and flexural strength and elastic modulus are important properties that may reflect the ability of the cement to manage stress without resulting into fracture and/or permanent deformation (15). Theoretically, the luting agent must have a value of elastic modulus between those of the dentin and restorative material (16). Differences in composition between materials may result in different physical properties and consequently influence their clinical performance. Thus, a proper knowledge of these differences may help in choosing the correct material for each indirect restoration clinical scenario.

The objective of this study was to evaluate the flexural strength and elasticity modulus of different commercial resin cements polymerized under different polymerization methods: direct light-curing, indirect light-curing with the aid of a pre-polymerized resin barrier, and self-curing. The hypothesis set was that the flexural strength and elasticity modulus of the dual-curing resin cements are similar or do not vary as a function of activation method employed.

\section{MATERIALS AND METHODS}

There were used: an indirect restoration composite (Sinfony, 3M ESPE, St. Paul, MN, USA) and four dual-cure composite resin cements: Rely ARC (Conventional/manually mixed, 3M ESPE), RelyX U100 (Self-adhesive/manually mixed, 3M ESPE), Clearfil Esthetic (Conventional/auto-mix, Kuraray Medical inc., Kurarashi, Japan) e Clearfil SA (Selfadhesive/auto-mix, Kuraray Medical inc.). Trade names, shades, manufacturers and composition of each material are described in Table 1.

\section{PREPARATION OF THE SPECIMENS}

A polyvinylsiloxane mold $(2 \mathrm{~mm}$ thick $\times 2 \mathrm{~mm}$ width $x 7 \mathrm{~mm}$ length) was used to fabricate the specimens. Fifteen specimens were made for each group ( $n=15)$. The specimens were prepared under room temperature $\left(23^{\circ} \mathrm{C} \pm 2\right)$ and in an environment using a yellow fluorescent light in order to avoid interference when polymerizing the specimens. The Rely ARC and RelyX U100 resin cements were dispensed trough the clicker dispenser delivering the same quantity of each paste onto a mixing pad, 
manually mixed and then placed onto the mold. The Clearfil Esthetic and Clearfil SA cements were dispensed using the manufacturers' auto-mixing tip, and then the mixed cement was delivered directly onto the mold. After mixing the dualcure cements according to the manufacturer's guidelines, the polyvinylsiloxane molds were accurately completed. A polyester tape (TDV, Pomeroy - SC, Brazil) was placed over the resin cement to press the material inside the mold.

\section{POLYMERIZATION METHODS}

The resin luting cements were evaluated according to three methods of polymerization (direct light-cure - group 1; indirect light-cure using a $2 \mathrm{~mm}$ composite resin barrier -group 2; and self-cure - group 3). For Group 1 (control) all the specimens were individually cured for $40 \mathrm{~s}$ using a LED light curing unit (Free Light Elipar, 3M ESPE, Seefeld, Germany) with a power of 1.554 $\mathrm{mW} / \mathrm{cm} 2$, which was measured with a Managing Accurate Resin Curing (MARCTM - Bluelight analytics inc., Halifax - Nova Scotia, Canada). For group 2 (experimental), specimens light cured using a composite shield with $2 \mathrm{~mm}$ thick, placed between the active tip of the curing unit and the resin cement. Group 3 (experimental) specimens were left to be self-cured. They were also stored inside a dark container (to avoid any light to reach them) after being inserted into the mold matrix. After 1 hour, all specimens from Group 1, 2 , and 3 were carefully removed from the molds and each specimen had its edges and corners removed with a fine scalpel blade number 15 , before being stored in deionized water at $37^{\circ} \mathrm{C}$ for 24 hours.

\section{FLEXURAL STRENGTH}

The flexural strength was determined according to ISO 4049. It was carried out using the test of the three points, using a universal testing machine (Instron 4411, Canton, MA, England), with a load cell of $50 \mathrm{kgf}$, operating at a speed of 0.5 $\mathrm{mm} / \mathrm{min}$ until failure of the specimen. The values of flexural strength in MPa were obtained. The device used to support the specimens consisted of two rods mounted parallel and below $5.0 \mathrm{~mm}$ apart from each other and a third point located in the center for the application of the force. A load-deformation graph was drawn. The flexural strength, $F$, was determined using the following equation: $F=3 \mathrm{PfL} / 2 \mathrm{WH} 2$.

Where Pf is the load measure applied to the specimen at the point of fracture, $L$ is the distance between the supports and the surface tension (5.0 $\mathrm{mm}), \mathrm{W}$ is the average width of the specimen, and $\mathrm{H}$ is the average thickness of the specimen.

\section{MODULUS OF ELASTICITY}

The modulus of elasticity was also determined according to ISO 4049. The elastic modulus, E, was obtained by tracing load versus deformation during testing of the three-point flexural strength previously described, using the following equation:

$$
E=(\Delta F / \Delta Y) \times(L 3 / 4 W H 3)
$$

Where $\Delta F / \Delta Y$ is the change in force $(\Delta F)$ per unit during deflection at the center of the specimen $(\Delta Y), L$ is the distance between the supports and the surface tension $(5.0 \mathrm{~mm}), W$ is the average width of the specimen, and $\mathrm{H}$ is the average thickness of the specimen.

\section{STATISTICAL ANALYSIS}

Flexural strength and elasticity modulus values were subjected to two-way ANOVA (resin cement vs. curing method) and Tukey post hoc test for multiple comparisons ( $a=0.05)$. 
SCANNING ELECTRON MICROSCOPY (SEM)

The fractured specimens' surfaces were morphologically analyzed. Samples were mounted on aluminum stubs, underwent ultrasonic cleaning bath for 10 minutes, and air-dried. The specimens were sputter-coated with gold (SCD 050 sputter coater, Fürstentum Liechtenstein), and observed with the aid of an scanning electron microscope (SEM; JEOL-5600 LV, JEOL, Tokyo, Japan) at 15 KV.

\section{CURING LIGHT IRRADIANCE MEASUREMENT}

The tip of the light-curing unit was directed onto a Managing Accurate Resin Curing (MARC ${ }^{\text {TM }}$ BlueLight analytics inc., Halifax - Nova Scotia, Canada) which is a spectral radiometer. The output of the spectrometer was plugged into a personal computer where software (SpectraSuite, Ocean Optics) calculated absolute radiance values and irradiance intensity during exposure time displaying them on the screen. The spectral power values were placed into a spreadsheet program (Excel 2003, Microsoft Corporation, Redmond, WA, USA), where the total radiant power was determined. One application was made for each testing condition: tip directly against the sample $(1 \mathrm{~mm})$, tip held at composite disc thickness $(+1 \mathrm{~mm})$ and tip held against composite disc $(+1 \mathrm{~mm})$. Output power values were divided by the tip fiber optic area to obtain irradiance values (power density; $\mathrm{mW} / \mathrm{cm}^{2}$ ), according to Figure 1 and 2.

\section{RESULTS}

Figures 1 and 2 show the single emission band of the LED curing unit (Freelight Elipar) over time and related to wavelength respectively. A power density of $1.554 \mathrm{~mW} / \mathrm{cm} 2$ was recorded when the tip was placed against the detector $(1 \mathrm{~mm})$. When the tip was held at distance equivalent to the composite disc thickness $(+1 \mathrm{~mm})$ (from the detector), the radiant power decreased up to 822
$\mathrm{mW} / \mathrm{cm} 2$. A lower power $(120 \mathrm{~mW} / \mathrm{cm} 2)$ was obtained when the composite disc $(1 \mathrm{~mm})$ was placed between the tip and the detector (the tip was placed against the disc) (Fig. 1).

Statistical analysis revealed that both factors were significant and also the interaction between them $(p<0.001)$. Consequently the hypothesis set in the present study must be rejected, as flexural strength and elasticity modulus values varied among the resin cements tested and in function of the polymerization method employed. All mean values regarding flexural strength and elasticity modulus are presented on Table 2. It was observed that the methods which used light (direct and indirect) produced statistically higher values than the ones produced by the self-curing method for Clearfil Esthetic and RelyX U100. For Clearfil SA no statistical difference was detected between the indirect method and the self-curing method, being them statistically lower than the direct method. On the other hand, RelyX ARC showed values with significant difference among the three methods evaluated. In the direct lightcuring method, RelyX ARC showed significantly higher values when compared to indirect method and self-curing method which obtained (the selfcuring) the significantly lowest mean value among the three methods. The Clearfil Esthetic Cement showed higher flexural strength mean values compared with the other resin cements among the three polymerization methods tested. The selfcuring method produced the lowest mean values regarding flexural strength.

Figure 3 (A-D) shows a series of scanning electron micrographs of different resin cements after mixing and subsequent polymerization. Entrapped big voids due to handling can be seen on fracture regions of the manually-mixed cements (RelyX ARC - Figure 3A and RelyX U100 - Figure 3B). Smaller voids are also observed in cements that used automatic mixing (Clearfil Esthetic Figure 3C and Clearfil SA Cement - Figure 3D). 


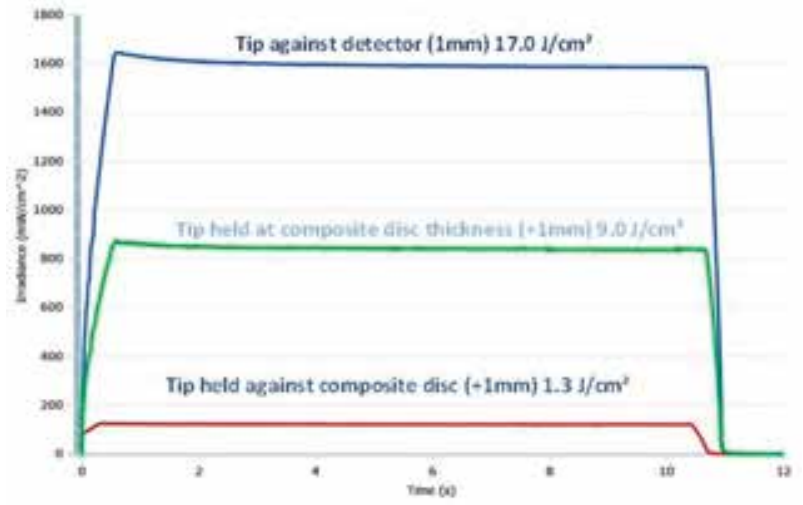

Figure 1. Graphic illustration of the irradiance delivered over time $\left(\mathrm{mW} / \mathrm{cm}^{2} / \mathrm{s}\right)$ recorded in three situations: against the detector (blue), at a distance equivalent of the resin barrier thickness (green) and against the resin barrier (red).

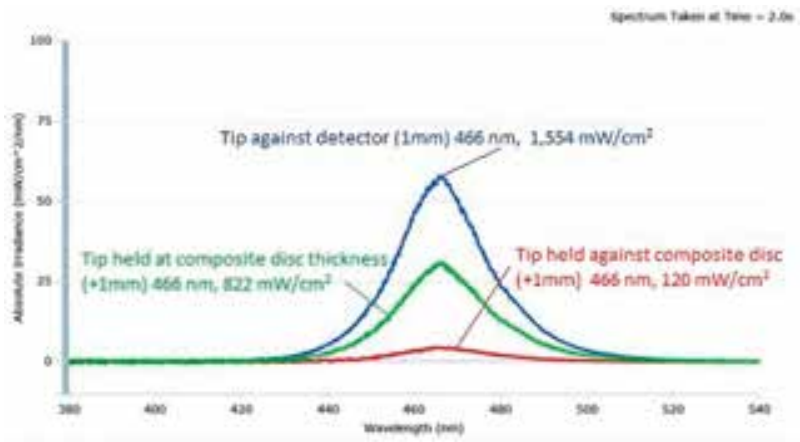

Figure 2. Graphic illustration of absolute irradiance (mW / cm2/ $\mathrm{nm}$ ) related to the wavelength peak of the light-curing unit recorded in three situations: against the detector (blue), at a distance equivalent of the resin barrier thickness (green) and against the resin barrier (red).

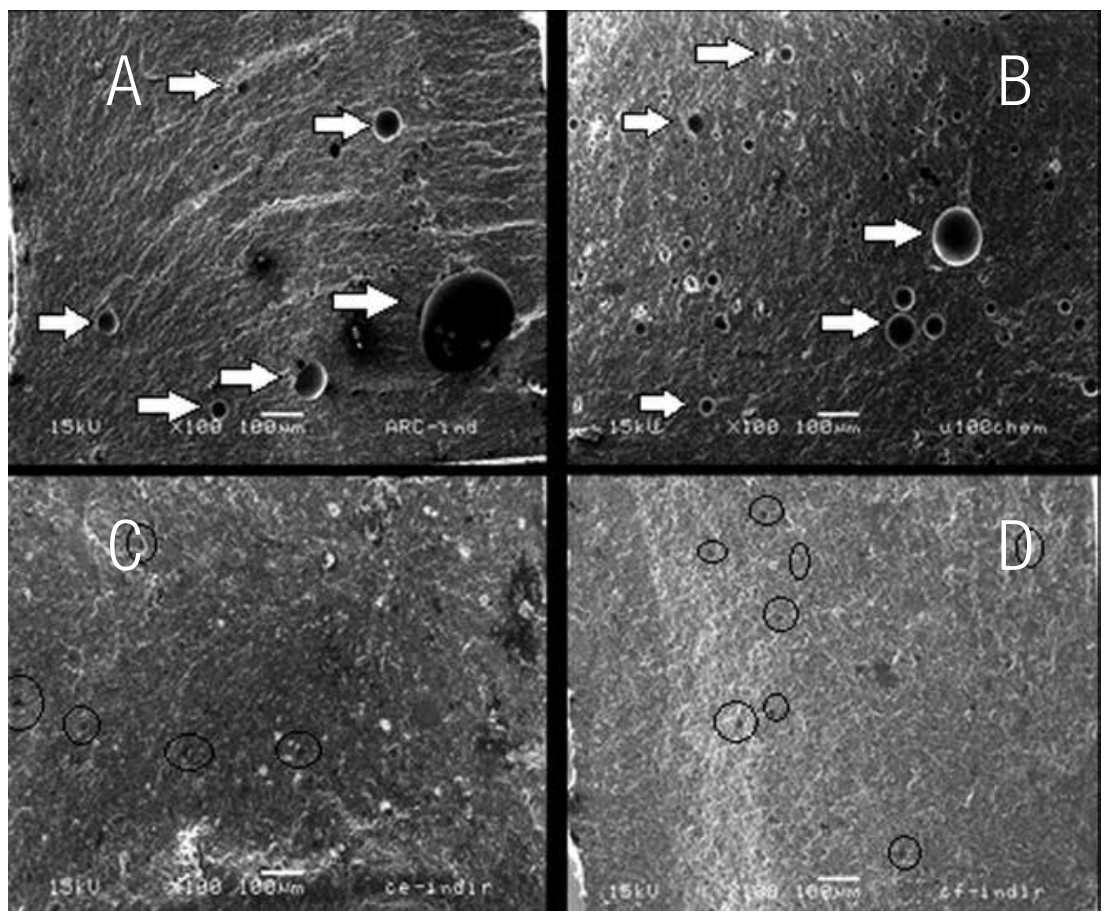

Figure 3. Scanning electron microscope images showing fracture surface topographies of four different resin cements after mixing and curing (100x magnification). (A) RelyX ARC (conventional/manually mixed), (B) RelyX U100 (self-adhesive/manually mixed), (C) Clearfil Esthetic (conventional/auto mix) (D), Clearfil SA Cement (self-adhesive/auto mix). White pointers and black circles show entrapped bubbles inside the cement specimen. 
DISCUSSION

This study showed that light-curing polymerization methods produce higher flexural strength and modulus of elasticity values than self-curing method on dual-cure resin cements. These results are consistent with other studies reporting that the influence of curing methods is dependent on the material, and that dual-cure resin cements particularly depend on photo activation to get improved flexural strength $(17,18)$. In this study, the results revealed a significant difference between the direct light-curing method and the self-curing method. The resin cements RelyX ARC and RelyX U100 showed 48\% reduction in values of flexural strength and modulus of elasticity when left to be self-cured. Clearfil Esthetic Cement and Clearfil SA cement showed reduction of around $41-42 \%$ (respectively) in the same parameters. Probably the reduction of mechanical properties happens because the initiation of chemical reaction (induced by the production of free radicals) is delayed by the manufacturers in order to let enough time for manipulation until it achieves its end. This is possible by the addition of large amounts of inhibitors on the resin cements' composition. Thus, this manufacturer's intervention possibly helped to decrease the mean values of mechanical properties of the resin cements when left to be selfcured (19). Additionally, resin cement formulations among manufacturers also vary (regarding chemical reaction components), and that may influence the resultant degree of conversion and the maximum polymerization rate of each cement (20). In summary, the lower degree of conversion exhibited by self-cured resin cements may be attributed to the low polymerization rate, as well to the delay on initiating the chemical polymerization reaction (21).

The degree of conversion is not the sole factor responsible for the mechanical properties of resin-based composites. Filler content (22) and monomer type (23) was found to be determinant factors on mechanical properties. The results of flexural strength and elasticity modulus obtained on the present study confirm this fact, since the average values of materials with similar chemical composition were not statistically different. RelyX ARC and the self-adhesive Clearfil SA Cement showed no statistical difference between them in all methods of activation. This fact may be explained by the similarity in chemical composition (Table 1 and 2).

The mechanical properties of resin-based luting agents have been evaluated using lightcuring methods through ceramic shields or indirect composite resin barriers in an attempt to approach in vitro studies to the clinical reality. For indirect light-curing method, RelyX ARC and Clearfil SA Cement showed lower mechanical properties than when the direct light-curing method was performed. This may be related to the fact that when the tip was held against composite disc, power density decreased 90\% (Fig. 2). Thus, this difference on cements mechanical properties may be attributed to variations in light intensity reaching the specimens $(24,25)$.

In contrast, Clearfil Esthetic Cement and RelyX U100 presented no statistical difference between the direct and the indirect polymerization methods. This demonstrates that for some materials, the flexural strength and elasticity modulus are less dependent on the activation mode after the beginning of the polymerization reaction (26). Some materials have a fast polymerization when exposed to light. This can be attributed to a higher content of photoinitiators on these materials. Consequently, those resin cements may have a high sensitivity to light exposure, even when the light reaching them may be attenuated by the indirect restoration to be luted. Thus, it is reasonable to expect that such dual-cure resin cements may have better mechanical properties and degree of conversion, even when the light intensity is attenuated. Many factors may be 
considered to pursue a successful cementation process of indirect restorations such as: curing light power density, tip-to-composite distance, spectral output of the emitted light, composite shade and photochemistry, and restoration thickness (27). Nevertheless, the results of this study suggest that despite the lower power density delivered when tip was held against the composite disc (120 mW/cm2), some materials may perform well, in this case both self-adhesive cements tested (RelyX U100 and Clearfil SA Cement). Thus it can be said that, most of the energy delivered when the tip was held against the composite disc was useful energy, and although low, it was sufficient to polymerize the resin cement. Also it is important to consider that materials from different manufacturers may be sensitive to different wavelengths depending on the photoinitiator type for example. Thus, it may be expected that each material react different from each other even under the same conditions, being impossible to predict their behavior based on their classification (conventional/ self-adhesive), but being totally dependent on composition differences between them (13).

Other factor that may be considered in the presentstudy is the handling process. A reduction in mechanical properties was recorded for RelyX ARC and RelyX U100 (manually mixed cements) and it may be explained by the fact that a manual mixing leads to a less uniform paste, promoting a greater formation of air bubbles due to the uncontrollable irregular movements performed when mixing by the operator. Although these air bubbles can reduce the stress generated by polymerization shrinkage (26), they can also function as stress concentration centers during the compression and traction where cracks can generate and propagate, producing a faster degradation of the material (27) and consequently leading it to failure. Thus, in order to reduce air trapping inside the resin cement mixture, the usage of auto-mixing systems must be encouraged as well as instruments that may deliver the cement directly to the restorations' surface such as appropriate syringes.

\section{CONCLUSION}

Within the limitations of this in vitro study, our findings suggest that:

- Light-curing significantly increased the flexural strength and elasticity modulus of all materials tested.

- The use of a $2 \mathrm{~mm}$ composite resin barrier did not affect flexural strength and elasticity modulus of the Clearfil Esthetic Cement and RelyX U100. However, the attenuation of light was responsible for the reduction on those mechanical properties of the two other materials.

- Conventional resin cements presented higher flexural strength and elasticity modulus than self-adhesive cements.

- The self-adhesive cements evaluated presented similar mechanical properties.

\section{ACKNOWLEDGEMENTS}

This project was partially supported by a grant from the Brazilian Government (CNPq \#307540/2009-0). 
Table 1. Description of materials used in the study.*

\begin{tabular}{|c|c|c|c|c|}
\hline Material & Manufactures & Composition & $\begin{array}{c}\text { Fillers } \\
\text { particles } \\
\text { (wt\%) }\end{array}$ & $\begin{array}{c}\text { Average } \\
\text { size of fillers } \\
\text { particles }(\mu \mathrm{m})\end{array}$ \\
\hline $\begin{array}{c}\text { RelyX ARC (A1) } \\
\text { (N100462) } \\
\text { Conventional }\end{array}$ & $\begin{array}{l}\text { 3M ESPE } \\
\text { St. Paul, } \\
\text { MN, USA }\end{array}$ & $\begin{array}{l}\text { Silane treated ceramic; triethylene glycol } \\
\text { dimethacrylate (TEGDMA); bisphenol a di- } \\
\text { glycidyl ether methacrylate (BISGMA); silane } \\
\text { treated silica; functionalized dimethacrylate } \\
\text { polymer; 2-benzotriazolyl-4-methylphenol; } \\
\text { 4-(dimethylamino)- benzeneethanol. }\end{array}$ & 67,5 & 1,5 \\
\hline $\begin{array}{c}\text { RelyX U100** (A2) } \\
(363426) \\
\text { Self-adhesive }\end{array}$ & $\begin{array}{l}\text { 3M ESPE } \\
\text { St. Paul, } \\
\text { MN, USA }\end{array}$ & $\begin{array}{l}\text { Silane treated glass powder, methacrylated } \\
\text { phosphoric acid esters, triethylene glycol } \\
\text { dimethacrylate (TEGDMA), silane treatead } \\
\text { silica, sodium persulfate, glass powder, subs- } \\
\text { tituted dimethacrylate, silane treatead silica, } \\
\text { sodium p-toluenesulfinate, calcium hydroxide. }\end{array}$ & 72,0 & $<9,5$ \\
\hline $\begin{array}{l}\text { Clearfil Esthetic } \\
\text { Cement (A1) } \\
\text { (0008AA) } \\
\text { Conventional }\end{array}$ & $\begin{array}{c}\text { Kuraray } \\
\text { Medical inc. Kurashiki, } \\
\text { Japan }\end{array}$ & $\begin{array}{l}\text { Bisphenol adiglycidylmethacrylate, triethylene } \\
\text { glycol dimethacrylate, hydrophobic aromatic } \\
\text { dimethacrylate, hydrophilic aliphatic dimetha- } \\
\text { crylate, silanated silica filler, silanated barium } \\
\text { glass filler, colloidal silica, dl-camphorquino- } \\
\text { ne, catalysts, accelerators, pigments, others. }\end{array}$ & 70,0 & 2,0 \\
\hline $\begin{array}{c}\text { Clearfil SA Cement } \\
\text { (A2) } \\
(0005 A A) \\
\text { Self-adhesive }\end{array}$ & $\begin{array}{c}\text { Kuraray } \\
\text { Medical inc. Kurashiki, } \\
\text { Japan }\end{array}$ & $\begin{array}{l}\text { Bisphenol adiglycidylmethacrylate, sodium } \\
\text { fluoride, triethylene glycol dimethacrylate, } \\
\text { 10-ethacryloyloxydecyl dihydrogen phospha- } \\
\text { te, hydrophobic aromatic dimethacrylate, hy- } \\
\text { drophobic aliphatic dimethacrylate, silanated } \\
\text { barium glass filler, silanated colloidal silica, } \\
\text { dl-camphorquinone, initiators, accelerators, } \\
\text { catalysts, pigments, others. }\end{array}$ & 66,0 & 2,5 \\
\hline
\end{tabular}

*Information provided by the manufacturer.

** The brand name of RelyX U100 is used in Latin America countries, while RelyX Unicem is used in USA and Europe. ( ) Batch numbers.

Table 2. Mean values and standard deviation of flexural strength (MPa) and elasticity modulus (GPa) obtained by the resin cements tested, in function of three activation methods.

\begin{tabular}{lcccccc}
\hline & \multicolumn{3}{c}{ Flexural Strength } & & \multicolumn{3}{c}{$\begin{array}{c}\text { Elasticity } \\
\text { Modulus }\end{array}$} \\
\cline { 2 - 7 } & \multicolumn{1}{c}{$\begin{array}{c}\text { Direct } \\
\text { method }\end{array}$} & $\begin{array}{c}\text { Indirect } \\
\text { method }\end{array}$ & $\begin{array}{c}\text { Self-cure } \\
\text { method }\end{array}$ & $\begin{array}{c}\text { Direct } \\
\text { method }\end{array}$ & $\begin{array}{c}\text { Indirect } \\
\text { method }\end{array}$ & $\begin{array}{c}\text { Self-cure } \\
\text { method }\end{array}$ \\
RelyX ARC & $150,0(26,1) \mathrm{bA}$ & $111,7(14,2) \mathrm{bB}$ & $77,9(19,6) \mathrm{bC}$ & $4,2(0,9) \mathrm{bA}$ & $2,5(0,5) \mathrm{bB}$ & $1,0(0,5) \mathrm{bC}$ \\
$\begin{array}{l}\text { Clearfil Esthetic } \\
\text { Cement }\end{array}$ & $219,0(39,9) \mathrm{aA}$ & $226,4(34,5) \mathrm{aA}$ & $129,0(51,6) \mathrm{aB}$ & $6,5(1,3) \mathrm{aA}$ & $5,8(1,0) \mathrm{aA}$ & $2,2(1,5) \mathrm{aB}$ \\
$\begin{array}{l}\text { RelyX U100 } \\
\text { Clearfil SA }\end{array}$ & $101,3(9,8) \mathrm{CA}$ & $94,9(36,9) \mathrm{bA}$ & $53,6(28,7) \mathrm{cB}$ & $2,9(0,5) \mathrm{cA}$ & $2,6(1,4) \mathrm{bcA}$ & $1,2(0,7) \mathrm{bB}$ \\
Cement & $113,6(19,6) \mathrm{bcA}$ & $80,6(23,7) \mathrm{bB}$ & $65,8(21,8) \mathrm{bcB}$ & $2,9(0,6) \mathrm{cA}$ & $1,5(0,4) \mathrm{cB}$ & $1,4(0,5) \mathrm{bB}$ \\
\hline
\end{tabular}

Same letters (upper case in row, lower case in column) indicate no statistical difference $(p<0.05)$. 


\section{REFERENCES}

1. Burke F. J. Trends in indirect dentistry: 3. Luting materials. Dent Update. 2005 Jun; 32(5): 251-4, 257-8, 260.

2. Christensen G. J. The rise of resin for cementing restorations. J Am Dent Assoc. 1993 Oct; 124(10): 104-5.

3. Tsukada G., Tokiwa K., Yamashita H., Ijichi H., Nagaoka S., Inoue K. Setting characteristics of resin cements. Japanese Journal of conservative dentistry. 199538 415-421.

4. Asmussen E., Peutzfeldt A. Bonding of dualcuring resin cements to dentin. J Adhes Dent. 2006 Oct; 8(5):299-304.

5. Hasegawa E. A., Boyer D. B., Chan D. C. Hardening of dual-cured cements under composite resin inlays. J Prosthet Dent. 1991 Aug; 66(2):187-92.

6. El-Mowafy O. M., Rubo M. H., el-Badrawy W. A. Hardening of new resin cements cured through a ceramic inlay. Oper Dent. 1999 Jan-Feb;24(1):38-44.

7. Arrais C. A., Miyake K., Rueggeberg F. A., Pashley D. H., Giannini M. Micromorphology of resin/dentin interfaces using 4th and 5th generation dual-curing adhesive/cement systems: a confocal laser scanning microscope analysis. J Adhes Dent. 2009 Feb; 11(1):15-26.

8. Breeding L. C., Dixon D. L., Caughman W. F. The curing potential of light-activated composite resin luting agents. J Prosthet Dent. 1991 Apr; 65 (4): 512-8.

9. Rode K. M., Kawano Y., Turbino M. L. Evaluation of curing light distance on resin composite microhardness and polymerization. Oper Dent 2007; 32: 517-8.

10. Rueggeberg F. A., Craig R. G. Correlation of parameters used to estimate monomer conversion in a light-cured composite. J Dent Res. 1988 Jun; 67(6):932-7.

11. 3M ESPE Product Profile.

12. Diaz-Arnold A. M., Vargas M. A., Haselton D. R. Current status of luting agents for fixed prosthodontics. J Prosthet Dent. 1999 Feb; 81(2):135-41.

13. De Munck J., Vargas M., Van Landuyt K., Hikita K., Lambrechts P., Van Meerbeek B. Bonding of an auto-adhesive luting material to enamel and dentin. Dent Mater.2004 Dec; 20(10):963-71.

14. Tezvergil-Mutluay A., Lassila L. V., Vallittu P. K. Degree of conversion of dual-cure luting resins light-polymerized through various materials. Acta Odontol Scand. 2007 Aug; 65(4):201-5.

15. Saskalauskaite E., Tam L. E., McComb D. Flexural strength, elastic modulus, and $\mathrm{pH}$ profile of self-etch resin luting cements. J Prosthodont. 2008 Jun; 17(4):262-8.

16. Li Z. C., White S. N. Mechanical properties of dental luting cements. J Prosthet Dent. 1999 May; 81(5):597-609.

17. Hofmann N., Papsthart G., Hugo B., Klaiber B. Comparison of photo-activation versus chemical or dual-curing of resin-based luting cements regarding flexural strength, modulus and surface hardness. J Oral Rehabil. 2001 Nov; 28(11):1022-8.

18. Braga R. R., Cesar P. F., Gonzaga C. C. Mechanical properties of resin cements with different activation modes. J Oral Rehabil. 2002 Mar; 29 (3): 257-62.

19. Rueggeberg F. A., Caughman W. F. The influence of light exposure on polymerization of dual-cure resin cements. Oper Dent. 1993 Mar-Apr; 18(2):48-55.

20. Pace L. L., Hummel S. K., Marker V. A., Bolouri A. Comparison of the flexural 
strength of five adhesive resin cements. J Prosthodont. 2007 Jan-Feb;16(1):18-24.

21. Cook W. D., Standish P. M. Polymerization kinetics of resin-based restorative materials. J Biomed Mater Res. 1983 Mar;17(2):275-82.

22. Chung K. H., Greener E. H. Correlation between degree of conversion, filler concentration and mechanical properties of posterior composite resins. J Oral Rehabil. 1990 Sep; 17(5):487-94.

23. Asmussen E., Peutzfeldt A. Influence of UEDMA BisGMA and TEGDMA on selected mechanical properties of experimental resin composites. Dent Mater. 1998 Jan; 14(1):51-6.

24. Rueggeberg F. A., Craig R. G. Correlation of parameters used to estimate monomer conversion in a light-cured composite. J Dent Res. 1988 Jun; 67(6):932-7.

25. Arrais C. A., Miyake K., Rueggeberg F. A., Pashley DH, Giannini M. Micromorphology of resin/dentin interfaces using 4th and 5th generation dual-curing adhesive/ cement systems: a confocal laser scanning microscope analysis. J Adhes Dent. 2009 Feb; 11(1):15-26.

26. Ferracane J. L., Greener E. H. The effect of resin formulation on the degree of conversion and mechanical properties of dental restorative resins. J Biomed Mater Res. 1986 Jan; 20(1):121-31.

27. Rueggeberg F. A., Cole M. A., Looney S. W., Vickers A., Swift E. J. Comparison of manufacturer-recommended exposure durations with those determined using biaxial flexure strength and scraped composite thickness among a variety of light-curing units. J Esthet Restor Dent. 2009;21(1):43-61.

28. Alster D., Feilzer A. J., De Gee A. J., Mol A., Davidson C. L. The dependence of shrinkage stress reduction on porosity concentration in thin resin layers. J Dent Res. 1992 Sep; 71(9):1619-22. Erratum in: J Dent Res 1993 Jan; 72(1):87.

29. Pegoraro T. A., da Silva N. R., Carvalho R. M. Cements for use in esthetic dentistry. Dent Clin North Am. 2007 Apr; 51(2):453-71. 